\title{
Cholesterol Metabolism in T Cells
}

\author{
Andreas Bietz ${ }^{1,2+}$, Hengyu Zhu ${ }^{1 \dagger}$, Manman Xue ${ }^{1}$ and Chenqi $\mathrm{Xu}^{1,3 *}$ \\ 'State Key Laboratory of Molecular Biology, Chinese Academy Center for Excellence in Molecular Cell Science, Shanghai \\ Institute of Biochemistry and Cell Biology, Chinese Academy of Sciences, University of Chinese Academy of Sciences, \\ Shanghai, China, ${ }^{2}$ University of Heidelberg, Heidelberg, Germany, ${ }^{3}$ School of Life Science and Technology, ShanghaiTech \\ University, Shanghai, China
}

Compartmentalization and spatial control of biochemical reactions is the foundation of cell-based life on earth. The lipid bilayer system employed by eukaryote cells not only keeps them separate from the environment but also provides a platform for key receptors to sense and interact with outside factors. Arguably one of the cell types most reliant on interactions of this kind, immune cells depend on their membrane to keep functioning properly. In this review, the influence of variation in cholesterol levels, a key component of lipid bilayer stability, on T cells will be discussed in detail. In comparison to other cells, $\mathrm{T}$ cells must be able to undergo rapid activation followed by proliferation. Furthermore, receptor colocalization is an important mechanism in this activation process. The impact

OPEN ACCESS

Edited by:

Hongbo Chi,

St. Jude Children's Research Hospital, United States

Reviewed by: Yousang Gwack, David Geffen School of Medicine at UCLA, United States

Cosima T. Baldari, University of Siena, Italy

*Correspondence:

Chenqi Xu

cqxu@sibcb.ac.cn

tThese authors have contributed equally to this work.

Specialty section:

This article was submitted

to T Cell Biology,

a section of the journal

Frontiers in Immunology

Received: 30 September 2017 Accepted: 13 November 2017

Published: 27 November 2017

Citation:

Bietz A, Zhu H, Xue M and Xu C (2017) Cholesterol Metabolism in T Cells.

Front. Immunol. 8:1664. doi: 10.3389/fimmu.2017.01664 of cholesterol availability on the processes of $\mathrm{T}$ cell proliferation and receptor sensitivity, as well as its potential for immunomodulation in disease treatment will be considered.

\section{Keywords: cholesterol, metabolism, T cell, disease, immunomodulation}

\section{CHOLESTEROL METABOLISM}

In the cell, cholesterol is largely responsible for being able to maintain a cell membrane with a certain degree of stiffness to it, removing the need for a rigid cell wall (1). This is due to its molecular tetracyclic structure, making it planar and rigid, as well as to the attached hydroxyl group which allows for orientation toward a polar solvent. It also serves as the substrate for a multitude of steroid-based hormones. Since it is so vital to every cell, the involved synthesis and regulatory pathways are nearly ubiquitous across cell populations (1).

\section{Biosynthesis}

There are two major ways for a cell to acquire cholesterol: it can scavenge cholesterol from its surroundings (blood stream, etc.) or it can synthesize cholesterol itself. While a sizable amount of cholesterol is indeed ingested by most humans every day via animal tissue, the ratio of scavenged cholesterol vs. synthesized cholesterol favors the internally produced version (2). To preserve homeostasis, a transport mechanism from regions of high cholesterol to regions of low cholesterol, as well as regions where excess cholesterol is disposed of, must exist. Since cholesterol cannot be transported via the blood stream, it is bound up in clusters of lipids and proteins, either in the form of high-density lipoprotein (HDL) or low-density lipoprotein (LDL). Both categories have distinct regulatory mechanisms (2).

In the cell, cholesterol is synthesized from acetyl-coenzyme A, which is soon converted to hydroxymethylglutaryl-coenzyme A (HMG-CoA). This precursor goes through a multistep enzymatic reaction via intermediaries like mevalonate, squalene, and lanosterol until it eventually yields cholesterol. The biosynthesis is very well understood and documented by now. A less well-understood topic is the regulation of the metabolic pathway. 


\section{Regulatory Mechanisms}

The primary signaling molecule at work in the cholesterol pathway is without a doubt cholesterol itself. Synthesis of more cholesterol is regulated via a feedback mechanism. Exogenous cholesterol therefore also decreases synthesis and vice versa. The main regulatory mechanisms will be showcased based on signaling in either a low-oxysterol or a high-oxysterol state (3).

The key protein for cholesterol sensing is sterol response element-binding protein (SREBP). This protein is situated in the ER membrane, bound to a second protein called SREBP cleavage-activating protein (SCAP). Normally, these two proteins move from the ER and to the Golgi apparatus, where SREBP is processed further. SCAP functions as mediator of this transport (4).

In high-oxysterol situations, however, another protein called insulin-induced gene protein (INSIG) is present in the ER and binds to SCAP. This binding keeps the SREBP-SCAP pair rooted in the ER membrane. Only in a low-oxysterol environment does INSIG disassociate from SCAP, enabling further processing. Once transported to the Golgi apparatus, SREBP is cleaved by site- 1 and 2 proteases ( $1 \mathrm{P}$ and $\mathrm{S} 2 \mathrm{P}$ ), yielding its active transcription factor (TF) form (5). This TF fragment then migrates to the nucleus and modulates expression of enzymes responsible for the biosynthesis pathway (HMG-CoA synthase, HMG-CoA reductase, farnesyl diphosphate synthase, squalene synthase, etc.), chief among them the rate-limiting enzyme HMG-CoA reductase (1). This manifold expression profile is divided between the different variants of SREBP, such as SREBP1a, SREBP1c, and SREBP2. SREBP1c and SREBP2 can be roughly categorized as regulators of fatty acid metabolism and cholesterol metabolism, respectively (4). In addition, SREBP2 also mediates lipid transport and lipoprotein uptake. SREBP1a targets genes in both categories, also including transport. There is a certain degree of redundancy to the signaling of SREBP1 and 2, and it has previously been demonstrated that this redundancy makes it possible for dysregulation of one component to be compensated by the other.

Conversely, there is a TF limiting intracellular cholesterol levels: liver X receptor. This receptor forms a heterodimer with retinoid $\mathrm{X}$ receptor and binds cholesterol (and other oxysterols) as well as 9-cis retinoic acid; hence, it is active in a high-cholesterol environment. There are two isoforms of the receptor, $\operatorname{LXR} \alpha$ and $\operatorname{LXR} \beta$ with distinct expression profiles. While $\mathrm{LXR} \alpha$ is primarily expressed in adipocyte and liver tissue, LXR $\beta$ is expressed more broadly, with enrichment in immune cells as well as heart and lungs. LXR has many downstream targets, most of them related to lipid metabolism. In reaction to sensing an excess of cholesterol, transferases such as cholesteryl ester transfer protein and ATB-binding cassette transporter A1 or G1 (ABCA1/ABCG1) mediate the efflux of cholesterol into HDL. Excess cholesterol is then transported to the liver either to be eventually excreted or converted to hormones and other molecules such as bile acid (6). The low-density lipoprotein receptor (LDLR) and the cholesterol esterification enzymes SOAT1/2 (alternative name ACAT1/2) also regulate intracellular cholesterol levels by changing the uptake rate or catalyzing conversion of cholesterol into cholesterol esters.

\section{Impact of Cholesterol Metabolism Defects}

Recalling the emphasis on the importance of cholesterol to every cell in the body, it is clear, that defects in the system will be reflected in drastic disorder in the body. Cholesterol is implicated in several diseases, particularly those prevalent in modern society such as atherosclerosis and Alzheimer's disease. While it is true that nutrition is a significant risk factor for many diseases involving cholesterol (particularly atherosclerosis), it is also important not to neglect potential disorders on a molecular level. At the elementary level, all cholesterol (as well as lipid metabolism in general) disorders are categorized either as hyperlipidemia or hypolipidemia, depending on which direction the dysregulation is exhibited $(7,8)$.

\section{Hypolipidemia}

Hypolipidemia is only rarely observed clinically. While this does not necessarily imply low prevalence in the population, it suggests that most cases are asymptomatic (as are those who are discovered in routine lipid screenings). While genetic disorders exist, which directly cause hypolipidemia (abetalipoproteinemia, hypobetalipoproteinemia, and chylomicron retention disease), it is most often observed as a symptom of a mostly unrelated systemic disorder, such as chronic inflammation, acute or chronic infection, undernutrition and hyperthyroidism among others (9).

\section{Hyperlipidemia}

Hyperlipidemia, also referred to as hypercholesterolemia or simply "high blood cholesterol," has shown an increasing incidence as well as prevalence in modern society. It can be classified as either primary (familial) or secondary (acquired), depending on the underlying causes. While the primary variant shows a relatively stable incidence relative to total population size, secondary hyperlipidemia incidence has increased over the course of recent decades (7).

Most cases of primary hyperlipidemia can be traced back to mutations in LDLR, apolipoprotein B, or proprotein convertase subtilisin/kexin type $9(10,11)$. Secondary hyperlipidemia on the other hand is usually associated with a high calorie diet or other metabolic disorders, such as diabetes. The health consequences of hyperlipidemia can potentially be life-threatening. The most commonly known consequence is without a doubt the accumulation of fatty material in the form of xanthomas on the lining of blood vessels. If left unchecked, this can eventually cause blockage of the blood vessel and thus heart attacks or stroke. There are other consequences, however, which are not as obvious. These more insidious malignancies are usually tied to the specific impact of cholesterol on the function of cells. The impact on T cells will be discussed in this review.

\section{CHOLESTEROL METABOLISM IN T CELLS}

Considering that cholesterol is important in maintaining cell membrane stiffness, its importance to immune cells, one of the cell types relying the most on motility and membrane-membrane interactions with other cells, is easy to see. Immune cells need to be able to move from tissue to tissue, need to be able to form a 
synapse with other cells, and sometimes even engulf target cells. While cholesterol is thus important for all subsets of immune cells, its importance to T cells will be examined here.

Since cholesterol can also be considered a kind of nutrient for the cell, it is first important to talk about how T cells manage their nutrients. Usually, a cell would derive energy from glycolysis, and oxidative phosphorylation, depending on how much oxygen is available to them. In highly proliferative cells, however, a much higher priority is placed on glycolysis $(12,13)$. One can observe this not only in proliferating T cells but also as the Warburg effect in cancer cells. Since proliferation requires lipids for membrane synthesis, fatty acid catabolic pathways are mostly suppressed in proliferative cells. In contrast, the mechanisms of fatty acid biosynthesis as well as cholesterol synthesis are strongly upregulated in T-cells (13).

Results regarding the cholesterol metabolism in different $\mathrm{T}$ cell subsets have so far been inconclusive. In one study (14), higher levels of GM1 were measured in thymic $\mathrm{CD}^{+}$single positive $\mathrm{T}$ cells when compared to $\mathrm{CD} 4^{+}$single positive $\mathrm{T}$ cells and $\mathrm{CD}^{+} \mathrm{CD}^{+}$double positive $\mathrm{T}$ cells. Splenic $\mathrm{CD} 8^{+} \mathrm{T}$ cells had higher levels of GM1 and total cholesterol than $\mathrm{CD}^{+} \mathrm{T}$ cells. No obvious difference of GM1 expression between naive and memory $\mathrm{T}$ cells was noted.

\section{Impact of Cholesterol on T Cell Activation and Proliferation}

Considering that $\mathrm{T}$ cell activation generally triggers a large-scale proliferation of the activated cells, anabolic pathways are critical during this process of activation. This has been well established in cancer cells, where high proliferation is the primary defining characteristic $(15,16)$. Treating a population of naïve $\mathrm{T}$ cells with Statin suppresses progression of their differentiation and cell cycle. Statin is an inhibitor of HMG-CoA reductase, the enzyme responsible for catalysis in the rate-limiting step of cholesterol biosynthesis. Furthermore, inhibition of this enzyme leads to decreased rates of DNA synthesis in many highly proliferative cell populations, such as lymphocytes, fibroblasts, and PDGFtreated smooth-muscle cells $(17,18)$. These downstream effects of statin treatment play a role in stagnating $\mathrm{T}$ cell activation. It is important to note, that not all statin-mediated changes in the cell are inherently tied to cholesterol levels. As statins inhibitory target is further upstream from cholesterol synthesis, cholesterolindependent effects may be at work as well.

Once a $\mathrm{T}$ cell receives an activation signal, sulfotransferase $2 \mathrm{~B} 1$ is upregulated to reduce oxysterol level, SREBP processing is promoted, and LXR signaling is suppressed (19). Induction of LXR signaling leads to stagnating proliferation, while a knockout confers a proliferative advantage. This link of LXR signaling to proliferation is directly related to cholesterol transport, as inactivation of the transporter proteins (e.g., ABCG1) prevents the effect of LXR induction. This showcases the importance of LXR as a metabolic checkpoint in T cell activation and immune cell function in general (19-21). SREBP has been shown to be indispensable for $\mathrm{CD}^{+} \mathrm{T}$ cell activation and proliferation as well (21). Metabolism checkpoints for $\mathrm{T}$ cell activation and proliferation can be found in many of the subset populations and include not only lipid metabolism but also glycolysis. mTOR and TRAF6, for example, have been shown to impact the differentiation of $\mathrm{CD}^{+}$ $\mathrm{T}$ cells via their downstream targets, regulating cell metabolism (22-26). Other important regulatory proteins, such as Myc and AMPK, have been implicated as well (27-29).

There is some evidence to suggest that the role of lipid metabolism may not be as simple as a binary toggle for proliferation. Since the rate of de novo fatty acid synthesis can impact differentiation either to $\mathrm{T}_{\mathrm{h}} 17$ or $\mathrm{T}_{\text {reg }}$ cells (30), a complex underlying regulatory system is implied.

The importance of understanding this relationship becomes clear when looking at cancer cases. The inability of T cells to cope with a developing tumor is aggravated as the energy consuming tumor decreases available nutrients in the body. If it reaches a point where blood LDL and HDL levels drop, even initial T cell activation can be compromised (31).

Exogenous cholesterol levels can shift the $\mathrm{T}$ cell population balance on the level of an entire organ in the body, as was observed in increased $\mathrm{T}_{\text {reg }}$ differentiation in hypercholesterolemic conditions in the liver (32).

\section{Lipid Rafts, Membrane Dynamics, and Nanoclustering}

Since the membrane is mostly made up of lipids, their dynamics impact the function of embedded proteins (33-35). Changing the charge of acidic phospholipids, for example, can directly alter TCR and CD28 activation (36-38).

These findings suggest one of the primary mechanisms by which cholesterol can change T cell activation: via changing dynamics of lipid rafts and the membrane in general and therefore increasing or decreasing the colocalization of crucial receptors. Lipid rafts can be categorized as heterogenous regions of lipid distribution across the membrane, which are distinct in their composition and fluidity. They represent one of the corralling mechanisms active in the cell membrane, since they allow for spatial control of membrane-associated proteins. The importance of lipid rafts, as well as their dependence on cholesterol concentration is well known (39-42). The immunological synapse has been considered a physiological form of a "lipid raft" (43). Using Miltefosine to disrupt normal lipid raft dynamics impacts $\mathrm{T}$ cell proliferation immensely, showing an over $50 \%$ reduced rate of proliferation.

Spatial control over receptors is especially crucial for receptors reliant on colocalization to achieve their active conformation (44). These receptors need to bind partner molecules and stay in stable association to function. Introducing a factor which promotes either the bound or unbound state modulates the overall sensitivity of the receptor. This kind of control over receptor clustering was shown to modulate sensitivity independent of the associated ligand (45). Maintaining precise spatial control over receptor nanoclustering partially determines sensitivity to external stimuli, as is the case for CD4 and the TCR (46). Lipids in general (and cholesterol in particular) can modulate receptor signaling via promotion of various conformational states of membrane receptors (37).

Not only colocalization of receptors on the membrane at large is implicated in this mechanism. Membrane fluidity and spatial 
control of receptors is crucial in maintaining one of the main avenues of communication for immune cells: the immunological synapse (47), since many of the involved proteins have to remain in close association.

\section{Cholesterol As Signaling Molecule in T Cells}

Apart from modifying membrane dynamics, cholesterol influences cellular signaling as direct ligand as well. Synthetic agonists to the LXR receptor family were shown to mediate an anti-inflammatory response in macrophages and other cells of the immune system $(48,49)$. The importance of these regulators of lipid metabolism to the innate immune system in general has been shown as well (50-53).
There are also cases, where it is still unclear whether the involved mechanism is related to direct cholesterol binding, or whether it is a downstream effect of the previously discussed modulation of membrane dynamics. Administration of squalene, a cholesterol precursor, was shown to increase the resting population of CD4 T helper cells as well as predispose T cells toward higher inflammatory reactivity (54) and direct depletion of cholesterol in the growth medium of T cells as well as diet of mice led to reduced rates of $\mathrm{T}$ cell activation and proliferation (55). It has been previously shown that rapidly dividing cell populations react to a higher demand for cholesterol with increased scavenging of serum LDL mediated via an increase of the responsible receptors (56).

Recently, the direct ligand role has gained some more momentum, however. Actual direct cholesterol binding modifies TCR

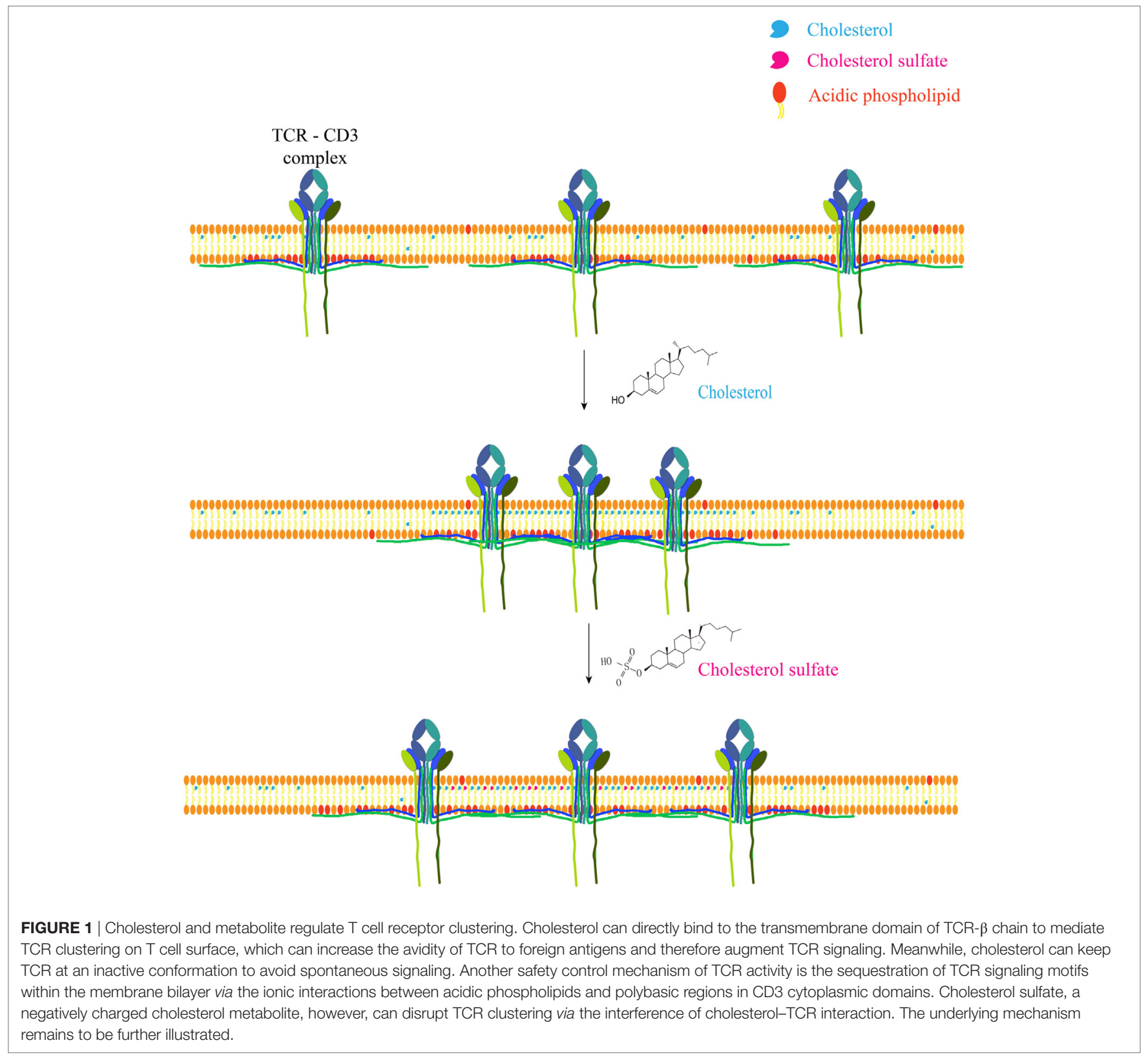


via allosteric signaling $(57,58)$ and a direct binding motif for cholesterol has been discovered and is present in a number of membrane proteins, such as the metabotropic glutamate receptor, adenosine receptor A1, and GABA type B receptor (59). Cholesteryl esters play a role as conformational stabilizers (or cofactor) in CD1c, allowing self-reactive $\mathrm{T}$ cells to bind the protein (60). Cholesterol sulfate (structurally similar to cholesterol) can disrupt TCR multimers, effectively inhibiting signal transduction. This most likely occurs due to displacing receptor bound cholesterol (61) (Figure 1).

\section{MODULATING T CELL FUNCTION VIA THE CHOLESTEROL PATHWAY}

Based on the demonstrated importance of cholesterol and its related regulatory proteins, it is easy to see the potential of some of these components as treatment targets. Potential applications as well as methods for making use of them will be discussed in the following.

\section{Tools for Modulation}

Statins are, of course, the most obvious and ubiquitous choice of drug intervention for modulating cholesterol metabolism. They have been widely used in atherosclerosis treatment for many years. While their actual effect has come under increasing scrutiny in recent years (62), statins remain an effective HMG-CoA reductase inhibitor. Atorvastatin can normalize $\mathrm{T}$ cell signaling and reduce the production of IL-10 and IL 6 by inhibiting cholesterol biosynthesis and reducing cholesterol levels in the $\mathrm{T}$ cell membrane (42). As a cholesterol-depleting reagent, methyl- $\beta$-cyclodextrin is used to disrupt lipid rafts and prevent their clustering, thus abrogating the heightened proximal TCR signaling and reversing the hyperactivity of T cells $(63,64)$. Synthetic agonists specific to a particular subset of the LXR receptor family have already demonstrated their effectiveness (65). By now, many drugs which target LXR specifically are available (66). The impact on $\mathrm{T}$ cells has also been shown with decreased cell proliferation and colony formation rates (67). Treatment options also include the precursors of cholesterol in the biosynthesis pathway, some of which have more favorable qualities in terms of bioavailability. Squalene treatment increases resting CD4 T cell population and desmosterol functions as an effective LXR agonist and SREBP repressor $(54,68)$.

As most signaling of $\mathrm{T}$ cells is mediated via surface proteins, these proteins form a very attractive target for modulation. There have already been studies trying to modulate $\mathrm{T}$ cell function via these receptors (69) in traditional, antibody-based ways. Modulating the receptor clustering to increase receptor sensitivity, however, is a promising approach for modulation without the need of expensive antibodies or other vehicles. For example, small molecule-mediated inhibition of ACAT1 can cause better TCR clustering in CD8 T cells (44).

\section{Potential Treatment Applications}

Metabolism has long been a target for cancer treatment (70). Usually, the treatments target the metabolism of cancer cells to deprive them of nutrients. Targeting the metabolism of antitumor immune cells instead may provide new treatment options. It is clear that immune cells undergo significant changes in the tumor microenvironment. Some of these changes may be mediated by metabolism signaling $(71,72)$. ACAT1 inhibition, leading to higher levels of plasma membrane cholesterol, induces higher antitumor activity in CD8 T cells (44) via enhanced receptor clustering on the cell surface. Under the same principle, modulation of cholesterol levels can decrease colocalization of crucial receptors in autoimmune diseases such as systemic lupus erythematosus (42). As such, it could potentially take the role of a sliding scale for sensitivity of $\mathrm{T}$ cells in general. Whether it is applicable in other diseases, such as long-term treatment of atherosclerosis via atorvastatin to inhibit the inflammatory response of CD4 T cells remains controversial $(73,74)$.

Using targets in metabolism for cell modulation always carries a risk of off-target activity. Interestingly, Cre-lox-based knockout of SCAP (and therefore SREBP1 and 2) led to asymptomatic phenotypes in the observed $\mathrm{T}$ cell populations, as long as they remained in a quiescent state. This suggests that quiescent cells could remain largely untouched from modifying these response elements (21).

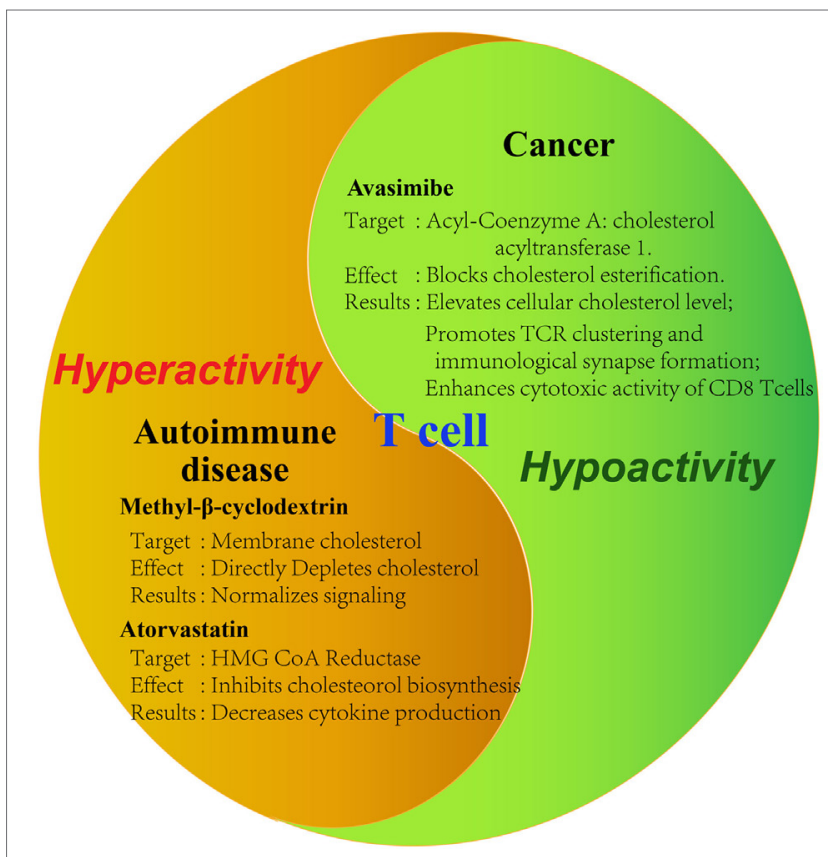

FIGURE 2 | Tools for modulating cholesterol metabolism of T cells. Summary of demonstrated tools for the modulation of $\mathrm{T}$ cell activity by targeting cholesterol metabolism in disease contexts. Tumor-infiltrating T cells are characteristic of hypoactivity, whereas auto-reactive $T$ cells are of hyperactivity. Therefore, different strategies should be applied to modulate cholesterol metabolism in different disease contexts. Specific reagents as well as the observed effects on the cell are summarized. Avasimibe: inhibitor of acyl-coenzyme A: cholesterol acyltransferase; GW3865: agonist of liver X receptor; methyl- $\beta$-cyclodextrin: strong cholesterol binder that can deplete membrane cholesterol; atorvastatin: inhibitor of hydroxymethylglutarylcoenzyme A (HMG-CoA) reductase. 
As has been demonstrated in numerous studies now, cholesterol is important in the activation and proliferation of $\mathrm{T}$ cells. From this conclusion, the thought of utilizing this for treatment of diseases arises. Initial studies examining the effect of modulating cholesterol levels on cancer and autoimmune diseases already show promising results (Figure 2). Counteracting the immunosuppressive tumor microenvironment, for example, could be an important aspect of all cancer therapies, potentially raising their chances of success across the board.

\section{Conclusion and Perspectives}

In recent years, the physiological and pathological importance of cholesterol metabolism in $\mathrm{T}$ cell immunity starts to be revealed, but we are still at the early stage to fully understand its roles and regulatory mechanisms. Modulating cholesterol metabolism appears to be a promising therapeutic direction to harness $\mathrm{T}$ cell activity in cancer and autoimmunity. Several key questions remain to be answered in the future: 1 . What are the function of various cholesterol metabolites in T cells? 2. Why do different $\mathrm{T}$ cell subsets have different cholesterol metabolisms and what

\section{REFERENCES}

1. Myant NB. Cholesterol metabolism. J Clin Pathol Suppl (Assoc Clin Pathol) (1973) 5:1-4. doi:10.1136/jcp.s1-5.1.1

2. Cox RA, Garcia-Palmieri MR. Cholesterol, triglycerides, and associated lipoproteins. In: Walker HK, Hall WD, Hurst JW, editors. Clinical Methods: The History, Physical, and Laboratory Examinations. Boston: Butterworth (1990). p. 154-6.

3. Olkkonen VM, Beaslas O, Nissila E. Oxysterols and their cellular effectors. Biomolecules (2012) 2:76-103. doi:10.3390/biom 2010076

4. Eberle D, Hegarty B, Bossard P, Ferre P, Foufelle F. SREBP transcription factors: master regulators of lipid homeostasis. Biochimie (2004) 86:839-48. doi:10.1016/j.biochi.2004.09.018

5. Shao W, Espenshade PJ. Sterol regulatory element-binding protein (SREBP) cleavage regulates Golgi-to-endoplasmic reticulum recycling of SREBP cleavage-activating protein (SCAP). JBiol Chem (2014) 289:7547-57. doi:10.1074/jbc.M113.545699

6. Li T, Chiang JY. Regulation of bile acid and cholesterol metabolism by PPARs. PPAR Res (2009) 2009:501739. doi:10.1155/2009/501739

7. Nelson RH. Hyperlipidemia as a risk factor for cardiovascular disease. Prim Care (2013) 40:195-211. doi:10.1016/j.pop.2012.11.003

8. Minicocci I, Santini S, Cantisani V, Stitziel N, Kathiresan S, Arroyo JA, et al. Clinical characteristics and plasma lipids in subjects with familial combined hypolipidemia: a pooled analysis. J Lipid Res (2013) 54:3481-90. doi:10.1194/ jlr.P039875

9. Elmehdawi R. Hypolipidemia: a word of caution. Libyan J Med (2008) 3:84-90. doi:10.4176/071221

10. Lye SH, Chahil JK, Bagali P, Alex L, Vadivelu J, Ahmad WA, et al. Genetic polymorphisms in LDLR, APOB, PCSK9 and other lipid related genes associated with familial hypercholesterolemia in Malaysia. PLoS One (2013) 8:e60729. doi:10.1371/journal.pone.0060729

11. Fisher WR, Zech LA, Stacpoole PW. ApoB metabolism in familial hypercholesterolemia. Inconsistencies with the LDL receptor paradigm. Arterioscler Thromb (1994) 14:501-10. doi:10.1161/01.ATV.14.4.501

12. Buck MD, Sowell RT, Kaech SM, Pearce EL. Metabolic instruction of immunity. Cell (2017) 169:570-86. doi:10.1016/j.cell.2017.04.004

13. Fox CJ, Hammerman PS, Thompson CB. Fuel feeds function: energy metabolism and the T-cell response. Nat Rev Immunol (2005) 5:844-52. doi:10.1038/ nri1710

14. de Mello Coelho V, Nguyen D, Giri B, Bunbury A, Schaffer E, Taub DD. Quantitative differences in lipid raft components between murine CD4+ and CD8+ $\mathrm{T}$ cells. BMC Immunol (2004) 5:2. doi:10.1186/14712172-5-2 is the functional importance of this difference? 3 . In different disease contexts, how does local environment affect cholesterol metabolism of $\mathrm{T}$ cells and how can this process be modified to rescue $\mathrm{T}$ cell activity? Answering these questions can eventually lead to the development of new cholesterol-based immunotherapies against various human diseases.

\section{AUTHOR CONTRIBUTIONS}

$\mathrm{CX}$ conceived the writing. $\mathrm{AB}$ wrote the first version. $\mathrm{HZ}$ revised the paper and made the figures. MX contributed to figure discussion.

\section{ACKNOWLEDGMENTS}

We thank Wei Wu for thoughtful discussion. CX is funded by NSFC grants (No. 31370860, No. 31425009, No. 31530022, and No. 31621003), and CAS grants (Strategic Priority Research Program No. XDB08020100).

15. Freed-Pastor WA, Mizuno H, Zhao X, Langerød A, Moon SH, RodriguezBarrueco R, et al. Mutant p53 disrupts mammary tissue architecture via the mevalonate pathway. Cell (2012) 148:244-58. doi:10.1016/j.cell.2011.12.017

16. Guo D, Prins RM, Dang J, Kuga D, Iwanami A, Soto H, et al. EGFR signaling through an Akt-SREBP-1-dependent, rapamycin-resistant pathway sensitizes glioblastomas to antilipogenic therapy. Sci Signal (2009) 2:ra82. doi:10.1126/ scisignal.2000446

17. Chakrabarti R, Engleman EG. Interrelationships between mevalonate metabolism and the mitogenic signaling pathway in $\mathrm{T}$ lymphocyte proliferation. J Biol Chem (1991) 266:12216-22.

18. MacIver NJ, Michalek RD, Rathmell JC. Metabolic regulation of T lymphocytes. Annu Rev Immunol (2013) 31:259-83. doi:10.1146/annurev-immunol032712-095956

19. Bensinger SJ, Bradley MN, Joseph SB, Zelcer N, Janssen EM, Hausner MA, et al. LXR signaling couples sterol metabolism to proliferation in the acquired immune response. Cell (2008) 134:97-111. doi:10.1016/j.cell.2008.04.052

20. Bischoff ED, Daige CL, Petrowski M, Dedman H, Pattison J, Juliano J, et al. Non-redundant roles for LXRalpha and LXRbeta in atherosclerosis susceptibility in low density lipoprotein receptor knockout mice. J Lipid Res (2010) 51:900-6. doi:10.1194/jlr.M900096

21. Kidani Y, Elsaesser H, Hock MB, Vergnes L, Williams KJ, Argus JP, et al. Sterol regulatory element-binding proteins are essential for the metabolic programming of effector T cells and adaptive immunity. Nat Immunol (2013) 14:489-99. doi:10.1038/ni.2570

22. Pearce EL, Walsh MC, Cejas PJ, Harms GM, Shen H, Wang LS, et al. Enhancing CD8 T-cell memory by modulating fatty acid metabolism. Nature (2009) 460:103-7. doi:10.1038/nature08097

23. Araki K, Turner AP, Shaffer VO, Gangappa S, Keller SA, Bachmann MF, et al. mTOR regulates memory CD8 T-cell differentiation. Nature (2009) 460:108-12. doi:10.1038/nature08155

24. Ip WKE, Hoshi N, Shouval DS, Snapper S, Medzhitov R. Anti-inflammatory effect of IL-10 mediated by metabolic reprogramming of macrophages. Science (2017) 356:513-9. doi:10.1126/science.aal3535

25. Laplante M, Sabatini DM. Regulation of mTORC1 and its impact on gene expression at a glance. J Cell Sci (2013) 126:1713-9. doi:10.1242/jcs.125773

26. Saxton RA, Sabatini DM. mTOR signaling in growth, metabolism, and disease. Cell (2017) 168:960-76. doi:10.1016/j.cell.2017.02.004

27. Wang R, Green DR. Metabolic checkpoints in activated T cells. Nat Immunol (2012) 13:907-15. doi:10.1038/ni.2386

28. Blagih J, Coulombe F, Vincent EE, Dupuy F, Galicia-Vázquez G, Yurchenko E, et al. The energy sensor AMPK regulates $\mathrm{T}$ cell metabolic adaptation and effector responses in vivo. Immunity (2015) 42:41-54. doi:10.1016/j.immuni. 2014.12.030 
29. Wang R, Dillon CP, Shi LZ, Milasta S, Carter R, Finkelstein D, et al. The transcription factor Myc controls metabolic reprogramming upon $\mathrm{T}$ lymphocyte activation. Immunity (2011) 35:871-82. doi:10.1016/j.immuni. 2011.09.021

30. Berod L, Friedrich C, Nandan A, Freitag J, Hagemann S, Harmrolfs K, et al. De novo fatty acid synthesis controls the fate between regulatory $\mathrm{T}$ and T helper 17 cells. Nat Med (2014) 20:1327-33. doi:10.1038/nm.3704

31. Wang L, Chi PD, Chen H, Xiang J, Xia ZJ, Zhang YJ. Low level of highdensity lipoprotein cholesterol correlates with poor prognosis in extranodal natural killer/T cell lymphoma. Tumour Biol (2014) 35:2141-9. doi:10.1007/ s13277-013-1284-Z

32. Mailer RKW, Gistera A, Polyzos KA, Ketelhuth DFJ, Hansson GK. Hypercholesterolemia induces differentiation of regulatory T cells in the liver. Circ Res (2017) 120:1740-53. doi:10.1161/CIRCRESAHA.116.310054

33. Wu W, Yan C, Shi X, Li L, Liu W, Xu C. Lipid in T-cell receptor transmembrane signaling. Prog Biophys Mol Biol (2015) 118:130-8. doi:10.1016/ j.pbiomolbio.2015.04.004

34. Wu W, Shi X, Xu C. Regulation of $\mathrm{T}$ cell signalling by membrane lipids. Nat Rev Immunol (2016) 16:690-701. doi:10.1038/nri.2016.103

35. Li LY, Shi XS, Guo XD, Li H, Xu CQ. Ionic protein lipid interaction at the plasma membrane: what can the charge do? Trends Biochem Sci (2014) 39:130-40. doi:10.1016/j.tibs.2014.01.002

36. Shi X, Bi Y, Yang W, Guo X, Jiang Y, Wan C, et al. Ca2+ regulates T-cell receptor activation by modulating the charge property of lipids. Nature (2013) 493:111-5. doi:10.1038/nature11699

37. Guo X, Yan C, Li H, Huang W, Shi X, Huang M, et al. Lipid-dependent conformational dynamics underlie the functional versatility of T-cell receptor. Cell Res (2017) 27:505-25. doi:10.1038/cr.2017.42

38. Li L, Guo X, Shi X, Li C, Wu W, Yan C, et al. Ionic CD3-Lck interaction regulates the initiation of T-cell receptor signaling. Proc Natl Acad Sci U S A (2017) 114:E5891-9. doi:10.1073/pnas.1701990114

39. Honigmann A, Mueller V, Ta H, Schoenle A, Sezgin E, Hell SW, et al. Scanning STED-FCS reveals spatiotemporal heterogeneity of lipid interaction in the plasma membrane of living cells. Nat Commun (2014) 5:5412. doi:10.1038/ ncomms6412

40. Hou TY, McMurray DN, Chapkin RS. Omega-3 fatty acids, lipid rafts, and T cell signaling. Eur J Pharmacol (2016) 785:2-9. doi:10.1016/j. ejphar.2015.03.091

41. Jiang H, Badralmaa Y, Yang J, Lempicki R, Hazen A, Natarajan V. Retinoic acid and liver $\mathrm{X}$ receptor agonist synergistically inhibit HIV infection in CD4+ T cells by up-regulating ABCA1-mediated cholesterol efflux. Lipids Health Dis (2012) 11:69. doi:10.1186/1476-511X-11-69

42. Jury EC, Isenberg DA, Mauri C, Ehrenstein MR. Atorvastatin restores Lck expression and lipid raft-associated signaling in $\mathrm{T}$ cells from patients with systemic lupus erythematosus. J Immunol (2006) 177:7416-22. doi:10.4049/ jimmunol.177.10.7416

43. Simons K, Gerl MJ. Revitalizing membrane rafts: new tools and insights. Nat Rev Mol Cell Biol (2010) 11:688-99. doi:10.1038/nrm2977

44. Yang W, Bai Y, Xiong Y, Zhang J, Chen S, Zheng X, et al. Potentiating the antitumour response of CD8(+) T cells by modulating cholesterol metabolism. Nature (2016) 531:651-5. doi:10.1038/nature17412

45. Molnár E, Swamy M, Holzer M, Beck-García K, Worch R, Thiele C, et al. Cholesterol and sphingomyelin drive ligand-independent T-cell antigen receptor nanoclustering. J Biol Chem (2012) 287:42664-74. doi:10.1074/jbc. M112.386045

46. Roh KH, Lillemeier BF, Wang F, Davis MM. The coreceptor CD4 is expressed in distinct nanoclusters and does not colocalize with T-cell receptor and active protein tyrosine kinase p56lck. Proc Natl Acad Sci U S A (2015) 112: E1604-13. doi:10.1073/pnas.1503532112

47. Dustin ML. The immunological synapse. Cancer Immunol Res (2014) 2:1023-33. doi:10.1158/2326-6066.CIR-14-0161

48. Glass CK, Saijo K. Nuclear receptor transrepression pathways that regulate inflammation in macrophages and T cells. Nat Rev Immunol (2010) 10: 365-76. doi: $10.1038 /$ nri2748

49. Joseph SB, Castrillo A, Laffitte BA, Mangelsdorf DJ, Tontonoz P. Reciprocal regulation of inflammation and lipid metabolism by liver $\mathrm{X}$ receptors. Nat Med (2003) 9:213-9. doi:10.1038/nm820

50. Joseph SB, Bradley MN, Castrillo A, Bruhn KW, Mak PA, Pei L, et al. LXR-dependent gene expression is important for macrophage survival and the innate immune response. Cell (2004) 119:299-309. doi:10.1016/j. cell.2004.09.032

51. Köberlin MS, Snijder B, Heinz LX, Baumann CL, Fauster A, Vladimer GI, et al. A conserved circular network of coregulated lipids modulates innate immune responses. Cell (2015) 162:170-83. doi:10.1016/j.cell.2015.05.051

52. Spann NJ, Garmire LX, McDonald JG, Myers DS, Milne SB, Shibata N, et al. Regulated accumulation of desmosterol integrates macrophage lipid metabolism and inflammatory responses. Cell (2012) 151:138-52. doi:10.1016/ j.cell.2012.06.054

53. Reddy P, Ocampo A, Suzuki K, Luo J, Bacman SR, Williams SL, et al. Selective elimination of mitochondrial mutations in the germline by genome editing. Cell (2015) 161:459-69. doi:10.1016/j.cell.2015.03.051

54. Surls J, Nazarov-Stoica C, Kehl M, Olsen C, Casares S, Brumeanu TD. Increased membrane cholesterol in lymphocytes diverts T-cells toward an inflammatory response. PLoS One (2012) 7:e38733. doi:10.1371/journal. pone.0038733

55. Chyu KY, Lio WM, Dimayuga PC, Zhou J, Zhao X, Yano J, et al. Cholesterol lowering modulates $\mathrm{T}$ cell function in vivo and in vitro. PLoS One (2014) 9:e92095. doi:10.1371/journal.pone.0092095

56. Ho YK, Faust JR, Bilheimer DW, Brown MS, Goldstein JL. Regulation of cholesterol synthesis by low density lipoprotein in isolated human lymphocytes. Comparison of cells from normal subjects and patients with homozygous familial hypercholesterolemia and abetalipoproteinemia. J Exp Med (1977) 145:1531-49. doi:10.1084/jem.145.6.1531

57. Schamel WW, Alarcon B, Hofer T, Minguet S. The allostery model of TCR regulation. J Immunol (2017) 198:47-52. doi:10.4049/jimmunol.1601661

58. Swamy M, Beck-Garcia K, Beck-Garcia E, Hartl FA, Morath A, Yousefi OS, et al. A cholesterol-based allostery model of T cell receptor phosphorylation. Immunity (2016) 44:1091-101. doi:10.1016/j.immuni.2016.04.011

59. Fantini J, Di Scala C, Evans LS, Williamson PT, Barrantes FJ. A mirror code for protein-cholesterol interactions in the two leaflets of biological membranes. Sci Rep (2016) 6:21907. doi:10.1038/srep21907

60. Mansour S, Tocheva AS, Cave-Ayland C, Machelett MM, Sander B, Lissin NM, et al. Cholesteryl esters stabilize human CD1c conformations for recognition by self-reactive T cells. Proc Natl Acad Sci U S A (2016) 113:E1266-75. doi:10.1073/pnas.1519246113

61. Wang F, Beck-Garcia K, Zorzin C, Schamel WW, Davis MM. Inhibition of $\mathrm{T}$ cell receptor signaling by cholesterol sulfate, a naturally occurring derivative of membrane cholesterol. Nat Immunol (2016) 17:844-50. doi:10.1038/ni.3462

62. Langsjoen PH, Langsjoen AM. The clinical use of HMG CoA-reductase inhibitors and the associated depletion of coenzyme Q10. A review of animal and human publications. Biofactors (2003) 18:101-11. doi:10.1002/ biof.5520180212

63. Krishnan S, Nambiar MP, Warke VG, Fisher CU, Mitchell J, Delaney N, et al. Alterations in lipid raft composition and dynamics contribute to abnormal $\mathrm{T}$ cell responses in systemic lupus erythematosus. JImmunol (2004) 172:7821-31. doi:10.4049/jimmunol.172.12.7821

64. Deng GM, Tsokos GC. Cholera toxin B accelerates disease progression in lupus-prone mice by promoting lipid raft aggregation. JImmunol (2008) 181:4019-26. doi:10.4049/jimmunol.181.6.4019

65. Collins JL, Fivush AM, Watson MA, Galardi CM, Lewis MC, Moore LB, et al. Identification of a nonsteroidal liver $\mathrm{X}$ receptor agonist through parallel array synthesis of tertiary amines. J Med Chem (2002) 45:1963-6. doi:10.1021/jm0255116

66. Hong C, Tontonoz P. Liver X receptors in lipid metabolism: opportunities for drug discovery. Nat Rev Drug Discov (2014) 13:433-44. doi:10.1038/nrd4280

67. Zhang R, Liu Z, Li Y, Wu B. LXR agonist regulates the proliferation and apoptosis of human T-cell acute lymphoblastic leukemia cells via the SOCS3 pathway. Int J Biochem Cell Biol (2016) 78:180-5. doi:10.1016/j.biocel.2016.07.007

68. Yang C, McDonald JG, Patel A, Zhang Y, Umetani M, Xu F, et al. Sterol intermediates from cholesterol biosynthetic pathway as liver $\mathrm{X}$ receptor ligands. J Biol Chem (2006) 281:27816-26. doi:10.1074/jbc.M603781200

69. Yao S, Zhu Y, Chen L. Advances in targeting cell surface signalling molecules for immune modulation. Nat Rev Drug Discov (2013) 12:130-46. doi:10.1038/ $\operatorname{nrd} 3877$

70. Galluzzi L, Kepp O, Vander Heiden MG, Kroemer G. Metabolic targets for cancer therapy. Nat Rev Drug Discov (2013) 12:829-46. doi:10.1038/nrd4145

71. Jiang Y, Li Y, Zhu B. T-cell exhaustion in the tumor microenvironment. Cell Death Dis (2015) 6:e1792. doi:10.1038/cddis.2015.162 
72. Biswas SK. Metabolic reprogramming of immune cells in cancer progression. Immunity (2015) 43:435-49. doi:10.1016/j.immuni.2015. 09.001

73. DuPage M, Bluestone JA. Harnessing the plasticity of CD4(+) T cells to treat immune-mediated disease. Nat Rev Immunol (2016) 16:149-63. doi:10.1038/ nri.2015.18

74. Guasti L, Maresca AM, Schembri L, Rasini E, Dentali F, Squizzato A, et al. Relationship between regulatory $\mathrm{T}$ cells subsets and lipid profile in dyslipidemic patients: a longitudinal study during atorvastatin treatment. BMC Cardiovasc Disord (2016) 16:26. doi:10.1186/s12872-016-0201-y
Conflict of Interest Statement: The authors declare that the research was conducted in the absence of any commercial or financial relationships that could be construed as a potential conflict of interest.

Copyright (C) 2017 Bietz, Zhu, Xue and Xu. This is an open-access article distributed under the terms of the Creative Commons Attribution License (CC BY). The use, distribution or reproduction in other forums is permitted, provided the original author(s) or licensor are credited and that the original publication in this journal is cited, in accordance with accepted academic practice. No use, distribution or reproduction is permitted which does not comply with these terms. 